\title{
CURRENT STATE AND PERSPECTIVES OF RESEARCH ON CONSTRUCTION MANAGEMENT AND MECHANISATION IN POLAND
}

\author{
Oleg Kapliński ${ }^{1}$, Witold Werner ${ }^{2}$, Andrzej Kosecki ${ }^{3}$, Janusz Biernacki ${ }^{3}$, Franciszek Kuczmarski ${ }^{4}$ \\ ${ }^{1}$ Poznan University of Technology, Division of Construction Engineering and Management, 60-965 Poznan, Poland \\ ${ }^{2}$ Housing Management Institute, 00-920 Warsaw, 1 Filtrowa St., Poland \\ ${ }^{3}$ Krakow University of Technology, Institute of Management in Construction Industry and Transport, Cracow, \\ 24 Warszawska St., Poland \\ ${ }^{4}$ Military University of Technology, Institute of Mechanical Engineering, 00-908 Warsaw, 2 Kaliski St., Poland
}

Received 23 July 2002; accepted 08 Oct 2002

\begin{abstract}
Current and intended research on construction management and mechanisation in Poland is the focus of this article. The discussion comprises four subject groups: investment process organisation, construction company operation, organisation and management methods, and mechanisation - including automation and robotisation in construction industry. Within all subject groups, an overview of the subject and analysis of the research state, as well as priority research trends have been presented.
\end{abstract}

Keywords: construction management, investment process, construction companies, mechanisation, automation, robotics, research, Poland.

\section{Introduction}

The issues of organisation and management in construction industry, which take into account the problems of economy and technology including mechanisation, covers an exceptionally wide spectrum of human activities. It is well rooted in the economic system. Therefore, an evolution of ground rules and conditions, as well as changes in research methods is well accentuated.

From the point of view of academic research, those issues have been overseen by the Committee of Civil Engineering of the Polish Academy of Sciences which celebrates its 50th anniversary in the year 2002. On that occasion, various Sections of the Committee have produced reports on the current status and the future perspectives of pertinent areas of research. This article presents the main ideas of the document [1]. The Section report was preceded by the analysis of the academic environment [2], and the review of main problems related to the research [3].

The report presents the following working theses:

- The scope of research has increased due to the technological and technical changes, changes in materials, services and production market structure and organisation, and changes in social expectations (political system shift); the building industry (including construction companies) operated in the reality of centrally controlled economy for the 40 out of 50 years covered by the report.
- Purely technical problems of construction are becoming less important: the capability to do construction work itself is no longer sufficient; what has become important is the issues of cost, time, and quality (in trying to win the market and the client);

- What is noticeable is a change in the trends: from taking interest in the issues of organisation to the issues of a more generally conceived management. Organising and organisation are clearly becoming a subject of management.

- Contemporary requirements of the construction industry market regarding the quality of work, keeping deadlines, and cost awareness, cannot be met if the forms of mechanisation and automation of processes are not perfected. This, in turn, is related to new problems of quality in designing mechanisation, considering not only technical, but also economical issues.

On this background, research problems present in the following areas should be very well accentuated:

- investment process organisation,

- construction company operation,

- organisation and management methods,

- as well as the issues of mechanisation, automation, and robotisation in construction processes.

The areas mentioned above will be discussed in that order. 


\section{Organising and managing investment processes}

\subsection{Overview of the subject and analysis of the research state}

The need to intensify both theoretical and applied aspects of the research of organising investment processes, and of the efficiency of management over those processes, is a result of significant technical and technological development in construction of buildings, creating new and modifying traditional materials, and growth of international competition.

The notion of investment processes usually comprises activities and efforts directed towards arriving at some designed effect, usually material in character (buildings and other material assets). An investment process, regardless its scientific angle (where the elements of interdisciplinary knowledge have a growing tendency to merge) is a form of enterprise but, unlike the industrial production, represents a non-repetitive form, involving a significant share of individual solutions and decisions [4, 5].

Part of the work done analysed the methodology preferred by UNIDO - the discounted cash flow methods (DCF). The basic assumptions and, simultaneously, basic effects of DCF methods consist in finding the right balance between investment expenditure (costs) and its effects, while an important part in this calculation is played by the factors of time (of construction, returns, operation of the concluded construction investment), and quality.

The significance of this branch of knowledge for the economy - on any scale - cannot be underestimated. It is assessed that the economically developed countries devote about a quarter of their Gross National Product on a wide spectrum of material investments. To rationalise such huge public expenditure is not solely an economic, but also a social and political problem.

In Poland, the issues of time of concluding investment projects, and of efficient utilisation of space, are becoming more and more important.

A shorter construction cycle than the cycle which is optimal for the contractor, does not always find a reflection in the designed cost calculation. The economics of investment is, therefore, more complex than the economics of construction industry.

The current research on time and utilisation of space in investment decisions is accompanied by the following phenomena:

- A business plan becomes the basic tool in the engineering, architectural and construction design, where a designer (a project manager) plays a crucial role of an advisor, becoming the investor's consultant.

- A growing demand for an array of complex investment services results in the growth of investment consultancy business.

- Traditional building companies more and more often evolve into real estate development companies. Those phenomena result in the development of new forms of organisation on the Polish market.
The investment project business plan, mentioned above, covers all significant problems which may occur in the process. It is a set of information and analyses involving a wider range of issues than the traditional feasibility study.

The spectrum of knowledge and information available during the phase of development of the business plan, as well as the depth of detail of the development have a crucial influence on the risk of not arriving at the projected effects.

Among the basic types of risk, the time risk comes into the foreground (the risk of delays in concluding the construction investment due to various reasons, mostly external), and the financial risk (exceeding the costs of construction, inability to reach the envisaged returns, higher costs). The research on risk in Poland is quite well advanced - cf [6].

The most difficult problem in the research on procedures related to organising and managing investment projects, including those depicted in business plans, is forecasting the economic growth nationally, in the selected segments and individual investors. In the light of advancing globalisation and in view of the symptoms of crisis in many countries, it is difficult to forecast real demand for all kinds of production and services, not convergent with social expectations. The difficulties lay, therefore, in defining capital return rate and discount rate, the rate of return, economic potential of consumers, investment results, etc.

Taking the listed Polish limitations into account, one may say that the knowledge and familiarity with the research areas pertinent to the discussed issues is not below the global level, nonetheless the way this knowledge is utilised in the national economy presents itself in a much worse light.

\subsection{Priority research trends}

Among the priority research trends and forecasts of development of control systems in investment processes, the following are crucial:

- The methods of defining capital and discount rates, expressed in percentages, used in calculating the rates and periods of return of investment processes for the purpose of business plans. Divergent views on the principles of base rate and correction ratios calculation methods result in huge discrepancies in the estimated values and, in effect, result in different investment decisions based on different assumptions. Furthermore, the research should include an influence of such elements on defining the percent rate as: return rate on Treasury bonds, discount rate on bills of exchange in the major banks, stock exchange indices, deposit rates offered by major banks, shift in percent rates abroad, etc.

- Principles of risk management in investment projects, especially commercial, for example, the real 
estate development projects. The efficiency of marketing is crucial in investment project management, ie the efficiency of the so-called marketing mix, or the " $5 P$ " principle, or: product, place, price, promotion, personnel.

- The ways of defining and assessing credibility and competitiveness of businesses operating in the area of investment activity. Creating conditions for the undisturbed flow of investment process is a basic problem here. One of the forms defining the credibility of companies involved in real estate development with a view to sell the product to a customer is the so-called developer certificate, issued by the National Construction Industry Chamber, investigated and granted by an independent Chapter. The certificate is granted on the basis of a number of documents defining the technical and economical standing of a company, and the range of guarantees offered to investors/customers.

To sum up: on the one hand, we need research on the choice of the method of defining the standing of investment companies, and the efficiency of the investment projects and, on the other hand, assessment of the possible changes in law, in macroeconomic conditions, national growth strategy, etc.

The market oriented character of the majority of investment projects exerts influence on the research on theoretical principles of rapid processing the external and internal data used in organising activities and management.

\section{Construction companies - organisation and management}

\subsection{Overview of the subject and analysis of the research state}

Construction companies (firms) are organisations (institutional structures) which operate within the framework of contemporary economy. The range of subjects pertinent to a construction company can be presented as follows:

- the influence of macroenvironment on the company,

- relationships between close environment (microenvironment) and the company,

- the company potential (interior).

A characteristic feature of the macroenvironment is that it strongly defines the operating conditions and the capacity for development in a company. Nevertheless, the company is unable to (except for very large and influential organisations) change those conditions. Therefore, there are phenomena, trends, fashions, etc, which need to be defined and forecast, nonetheless, those phenomena operate regardless of the influences of the company. They may give a company some new opportunities, but also pose dangers (hindrances).

What is characteristic of the close environment - the microenvironment - is that certain subjects and phenomena occur there which are directly related to the company.

What is usually called a potential is general re- sources and assets of the company, and the capability to put them into practice, which enable the company to survive and develop. The potential can be put under control, and the potential and its usage can be researched. Partial (confidential) results of the research do not usually enter into the circulation of scientific information; nevertheless, such research must be undertaken. The results of the research may become a foundation for defining the strengths and weaknesses of a company. In relation to opportunities and dangers, the research results may serve as a basis for the company strategy and development. In order to do this, one can use the integrated methods of company appraisal, such as SWOT, or SPACE [7].

Research done before 1989 was basically focused on the degree of adaptation of different elements in the company to the obligatory, unyielding principles of centrally controlled economy. Such research, for instance:

- there were attempts at defining the "optimal" size of a construction company, including its base and background, as well as the "optimal" national network of construction companies,

- measures were defined and degrees of specialisation of companies,

- issues of labour efficiency were discussed,

- new methods of planning activities were developed, which had no relationship with the practice, because there was no authentic demand for them,

- shortage of motivation for innovative thought was pointed at,

- influence of the company size on "production costs" was established.

Since 1990, companies have begun to operate in the emerging market economy; its development and, therefore, process of change continues until this day.

There have been major changes in the structure of construction companies in Poland. While in 1988, the average number of employees in a company was: 38 in Austria, 17 in Germany, 9 in the USA, 4 in France and the UK, in Poland the figure was 429. In 1988, this index for Poland was only 3 employees $(3,18$ to be precise). There were only 137 companies in Poland which employed 501 and more. The major companies co-exist, they need each other in their own well conceived interest. The problems of a major company differ from those experienced by a medium-size or small company.

The processes of transformation have been relatively well known - restructuring, consolidation, as well as problems emerging in transformation. Case studies have been published. The indication is that Polish companies have been taken over by foreign ones.

The hindrances and barriers of development of building companies have been researched.

Moreover, the following issues are investigated:

- marketing activities taken up by construction companies (it is suggested to introduce, for example, a System of Marketing Information - SIM),

- conditions and problems of introducing quality 
assurance systems in construction companies,

- efficiency-related activities initiated by construction companies with relation to market processes, and in view of growing competition.

The following areas have been little investigated:

- human resources management in a construction company, directions of training, in-service training, remuneration systems, problems of staff ageing, employment of young people;

- financial standing of construction companies, issues of financial fluency, problems of funding construction work;

- formal organisational structures of construction companies and their changes.

\subsection{Priority research trends}

Future research will deal with interdisciplinary problems, or issues "at the interface" of various disciplines. These will be largely decision related problems.

Following trends can be identified in research on the construction company:

- risk management - identification, analysis (especially quantitative) and reaction to risk. It is a very wide spectrum of research which integrates the research on: the influence of macroenvironment on the company, on the relationships between the company and the microenvironment, and on creating and using a company potential. In particular, attention should be paid to two situations - namely, taking up construction projects and entering economic alliances,

- the issues of company credibility,

- company market success or failure factors, including offering a range of new products (for instance, a two-in-one service of designing and construction),

- marketing activities (including research on setting up and operating marketing information systems),

- cost control,

- quality assurance systems (including a shift of approach from structural to process),

- utilisation of employers' skills (synergy management),

- logistic systems,

- making the most of the Internet (for example, a web site, e-business, financial transactions).

In national research, it is useful to make attempts at adapting the achievements of other countries who have been operating in the reality of a long-standing, solid market economy.

Apart from the basic research trends mentioned above, other current and near future fields of scientific interest can be identified:

- The influence of macroenvironment on the company, and the relationships with the close environment (opportunities, dangers, prosperity, obstacles). Such issues may be researched as, for example:

- company costs of certifications and approvals,

- the so-called "social costs" resulting from labour laws,
- financial load of deposits and guarantees,

- financial loads related to funding construction work,

- availability of the operational capital, required collateral,

- range of central and local government protectionism - what is the situation like in other countries,

- preferences for foreign companies - real or apparent?,

- opinions about lengthy administrative procedures.

- Methods of acquiring orders, including research on bidding decisions. It is a consequence of market development, as well as of the fact that construction services cannot be provided in advance, such services cannot be stored. The problem of bidding strategies is a research problem in itself.

- Trends in transformations and in generally conceived own investments in companies, including investments in modern technologies, and how to fund them; introducing innovations (diversification versus specialisation, competitiveness, consolidation efforts), in the light of Polish accession to the EEC. The idea of re-engineering has not been yet used in full, thus re-organisation of the company through concentrating on processes).

- Perfecting formal organisational structures, also in view of a full utilisation of staff and technical potential of the company in order to meet the expectations of the market and of international competition, including research on holding structures, as well as on flexibility of organisational structures related to the number and size of construction projects (building sites).

- Cooperation of management segments of the organisation with the teams in charge of the building sites (engineering and planning support, work safety support, etc).

- Information management with information technology support.

- Methods of analysing and sizing competition.

Purely technical problems related to questions of "how to do it?" recede to the background; the mere knowledge of conducting construction work is no longer enough; what has become crucial is the problems of costs, time, and quality - as well as all possible combinations of the three factors - trying to win the customer and the biggest share of the market.

\section{Development of organisation and management methods in construction industry}

\subsection{Overview of the subject and analysis of the state of research}

The systematically growing technological complexity of production processes is the reason why their prepa- 
ration and practical implementation require more and more efficient and fast planning and decision oriented methods. The organisational preparation of those processes taking into consideration what resources and financial means are at one's disposal is becoming ever more difficult, and competition on the construction market forces companies to look for the best solutions. It is perfecting organisational processes that provides a potential for lowering company's own costs incurred by those processes - it is becoming possible to formulate economically optimal practical implementations, well adjusted to the existing local conditions, thanks to good organisation and its influence on the time span of practical implementation of projects.

The last decade has clearly seen a development of methods based on sophisticated computer applications which require not only databases, but also knowledge bases. The first research work taking shape of expert systems have appeared in Poland, requiring operating knowledge bases, too [8]. There is a number of examples and proposals for practical implementations, in various academic centres, put forward in the form of hybrid methods. Some interesting results have been arrived at thanks to using the so-called heuristic methods which replace classical analytical methods. This is due to the specific character (structure) of the problem area, largely focused on analysing economic phenomena, saturated with uncertainty and non-linearity of relationships [9].

The growing complexity of processes is related to the origins and development of organisational methods, a history which can be drafted starting from the formulation of the first principles of scientific organisation of work, through development and gradual perfection of the basic organisational methods (still in use due to natural character of their interpretation and feasibility of use), to the current advanced scientific theory of organisation and management.

The first - currently regarded as traditional - methods of designing the organisational aspect of a project, and the economic analyses methods, the search for organisational solutions, and working out decisions for management was becoming less effective when the implemented projects were becoming technologically more and more complex.

The reason of insufficient effectiveness of those methods is, first of all, the fast growing information basis necessary to formulate a satisfactory and precise assessment of the current and forecast state, as well as a long time necessary to carry out the appropriate analyses. In order to take decisions fast and effectively, one needs a high rate of acquisition and processing of information - what is, therefore, necessary, is an available information basis, and proper means and methods of data processing.

The principle of modelling of an organised process in the form of a graph noting technological order of events which is used to describe different functions being the subject of research, is a foundation of those methods. The development of science of discipline of organisation and marketing, and the assisting disciplines, such as information technology, economics, applied mathematics, decision theory, mathematical statistics, etc, has become competitive on the international scale, and the emerging new methods of organisation, and other related methods - due to their significance, not only economical - have remained for many years, and perhaps still remain unavailable for the general users.

Transferring advanced theories into algorithms provided an opportunity to use fairly complex calculation methods in practice. The efficiency of those methods resulted in a bigger interest of the market in them, and noticeably increased funding of pertinent research.

Currently, the tendencies can be noticed to direct the research into five problem areas covering the following issues [10]:

- methodology,

- decision theory,

- numerical algorithms,

- practical implementation, and

- efficiency of usage of organisation and management methods.

It is believed that the development of organisation methods, in their theoretical aspect, could have been explained by means of network modelling. The existing generalised network theory allows for analytical or heuristic organisation of any given project both of explicit (determinist) structure of internal relationships depicted by logical formulas, and of stochastic structure and unrestricted parameter structure.

The network theory used mostly in modelling internal organisation of processes extended by the theory of systems, makes it possible to combine any undertaken project into the structures of existing environment and, therefore, goes towards the search of non-isolated solutions. In the practical use of theoretically complex methods of solving the issues of organisation, the advanced knowledge of the theory is not necessary.

It is, nonetheless, indispensable to have a proper "tool kit" at hand, whose theoretical basis can be a "black box" for the user, but the ability to manage it from the information technology standpoint at the "input", and full, precise interpretation and usage skills which enable to handle the information as a solution at the "output" are the primordial condition of success. Those issues seem to become a centre of interest on the marker of computer applications dealing with the problems of management. Such applications have become the main focus for many information technology companies geared towards the popular "management".

Another aspect of interpretation of organisation should be looked at, namely on the action-result relationship.

The traditional approach to the problems of organisation has been concentrated on action. The building works (in construction), or - in other words - activities (generally) have been main subjects of interest. The 
effect of an action was an expected, natural consequence proving the strength of an organisational solution.

In the methodological approach to problems of organisation, a different attitude has emerged, directed largely on the effect. This attitude, in practical terms, leads to interpreting the implementation of a process as a series of events. Therefore, any event which is significant from the standpoint of the problem is logically defined. The implementation continues from the start, through a series of events, until the end of the process, while all technological and organisational conditions are unchanged.

Thus, a complex problem of organising a process of implementation falls into many sub-parts which may be pertinent to the implementation of the process between the subsequent events, or be decisive about the further implementation of the process (operational strategy) beginning at the moment when a specific situation (a specific event) emerges. In order to be able to solve those problems, one needs access to assisting disciplines, such as operational research, and other.

An intensive development of methods for solving specific problems by means of the decision theory has been noticeable. This theory, in its elementary approach, associates the decision which is taken with the result (effect), and with an uncertainty of its occurrence.

The result, as an effect of a decision, being the primordial element of an organisation model, provides a direct basis for describing the function of uncertainty of arriving at it, and then a basis for recording the function of the related risk [11].

The problems of decisions which have the characteristics of processes are dealt with nowadays also by the so-called Interactive Decision Theory.

The need to use the currently existing, advanced theories in practice has led to constructing logical algorithms, software, and next, to the implementation and analysis of the utilisation effects. A certain distance can be observed between the advancement of theories and their practical usage. The popularity of using theoretical achievements seems to have at least two requirements to meet:

- education and training of management staff (engineers, managers), and

- a stimulated rate of introduction of the algorithms located in the system applications in computers into the marker (to the user).

The level of education of elitist groups of theoreticians of organisation in Poland is sufficient to implement work which will develop this discipline. The priority in utilising it is continuous education of engineering and managerial staff. The need for adjustment to European standards (also in usage of the principles of organisation and control over the implementation processes) also is of crucial importance.

There is a noticeable change of trends in the interest in the issues of organisation, going much more towards a generally conceived management. Organisation and organising are clearly becoming a subject of management. Management is looked upon as a dynamic decision-related process comprising all planning, organisational, implementation, and control elements pertinent to the subject of management. Organisation, from this standpoint, is regarded as a specific state of ordering (existing or intended) which changes structurally (or in its parameters) within the process of management. Thanks to this example, it is possible to notice the emerging modifications of definitions of notions, also basic notions, leading to a state of a certain chaos in the discipline. Nonetheless, introducing order in this respect is being done systematically.

The development of research and perfecting methods is inspired by activity and business needs. Those are the reasons responsible for special interest in, and development of this discipline. For many years to come, it is going to be the cheapest source of gaining economic effects.

\subsection{Priority research trends}

Methodological problems related to the organisation of practical implementation of construction projects currently focus on decisions regarding the choice of a traditional or network version of analyses, presentation, control, monitoring, and interference in the process of practical implementation.

As to the repeatable processes, characteristic of the construction industry and small construction companies (with little variety of construction work), the concepts of proposals of models to follow are discussed. In this respect, between 1994-1998 research was carried out in the EEC, within the framework of CORE (COnstruction companies process REengineering) research project.

The foremost problem focusing a special interest is the coherence of forecasting a future course implementation of a project with its real course of development.

There are many factors influencing the forecast precision - mainly the adequacy of description parameters depicting the characteristics of particular elements which constitute an organised structure of the process.

An essential role in assessing the values of parameters is played by the methods of estimation based on the results of real process observations. The research done independently by many authors, for instance American and Polish, has confirmed a strong influence of estimation methods on the precision of results (and indirectly on the forms of distribution curves).

Another basic problem in analysing the organisation of construction projects is the question of assessment of probability of arriving at a set target. A demand of particularly high level of precision of this estimate is posed while taking decisions burdened (endangered) by high level of risk. Problems of responsibility for safety in management emerge there. The issues of management do not exist without risk. 
A special group of problems and their solutions is related to controlling the processes of implementation of the project which had been technically, organisationally, and economically set up before. The systematic process of monitoring implementation, the assessment of its status, and a decision regarding a possible interference in order to introduce corrective changes to the process of implementation at any given time, require advanced methodological, procedural, and technical disposition.

Strengthening this disposition through developing analytical methods and specialist software fosters a clear cut progress in this respect.

An example illustrating the essence, as well as the wide range, of the issues of control of work progress throughout the whole project, and the level of costs incurred (Barraz model) is illustrated in [12], where a stochastic image of monitoring the state of integrated time and costs is presented Polish approach is found in [13].

In this context, the management concept is based on forecasting, on controlling the coherence between the current status and the forecast, and on interference. The most popular method of forecasting is computer simulation (for example, Monte Carlo (MCS) and @RISK for Project methods), which enables the stochastic description of integrated time of implementation and costs. Monitoring the (time-cost) status during implementation facilitates a comparative assessment of the status against the forecast, and allows to prepare an updated forecast which accounts for the current status, and aids the decision regarding further implementation. What it means is that the majority of organisation and management methods are now assisted by accessory software comprising means of production management and financing.

Such an approach facilitates not only the risk analysis, but also the cash flow analysis or, generally, control over construction companies taking the financial criterion into account. In Poland, research in this area should develop more dynamically.

The sphere of solving repeatable issues (systematic in the operation of small and medium-size construction companies) has focused some interest over the last few years. The search has been to find the ways to reduce the work load on selection as much as possible, and to prepare numerical information required for the problem analysis.

We have seen proposals being put forward of using properly modelled and specialised network structures which would solve the problems using analogue methods - the so-called artificial neurone networks. Their capability for "learning" allows to use the "knowledge" at hand to acquire information about the problem solution with exceptionally few items of current information needed. The artificial neurone networks (ANN) are being initially checked in their applications to the typical network analysis, regarding the implementation time of construction projects as well as, apparently with better prospects, in practical usage - to analyse the means of production, including finding optimum solutions [14].
This research trend should be continued, and further widened to cover management issues: real estate management, including housing potential control, repair works planning and real estate estimation.

\section{Mechanisation, automation, and robotisation in construction and engineering works}

\subsection{Overview of the subject and analysis of the research state}

Generally perceived construction industry in a meaningful participant of our everyday life - present in creating, implementing, and maintaining the infrastructure of human existence. Continuously growing costs and little growth of productivity of this "industry" compared to the expectations and swelling global population cause social frustration. One of the ways leading to alleviation of those problems seems to be to strive towards mechanisation and robotisation of the growing range of work (activities) in construction.

What is understood by mechanisation here, is using machinery and equipment alleviating and facilitating human labour, simplifying and prompting assembly work, and overseeing the transportation and completion and dosage of equipment and materials. Such machinery is controlled by an operator supervising their work.

In case of automation and robotisation of construction processes, on the other hand, the control system directly uses the information about the development of the processes in order to both formulate the procedures, and control the signals sent to control devices, while the human role is limited only to reacting to emergencies and failures resulting either from breakdowns of working elements, or the occurrence of events that the control system had been unable to predict, or to external risks [15].

Multitude of tasks and technologies used in construction, and using a variety of machines and equipment of different types, destination, size, and power, points at the need of multidirectional approach to the issues of mechanisation and automation of working processes carried out in the course of erecting a variety of structures and buildings. A number of structural-task systems can be indicated here [16-18]:

1. Re-shaping the ground surface;

2. Erecting constructions and buildings;

(Within this task/function group, automation and robotisation is justified not only by the reasons of work safety, but also by the necessity of reducing the duration of transport and assembly activities).

3. Spatial division of individual floors, fitting and assembly of elements of permanent equipment;

4. Fitting the interior with utility installations, decoration and finishing work;

(These two groups of tasks are difficult to automate and robotise, and the whole adaptation process must be preceded by changes in organisation and tech- 
nology related to the tasks, and design changes pertinent to the built-in elements and equipment).

5. Maintenance during the construction usage (including control work and cleaning, repair work and renovation).

(Multielement manipulators are envisaged here, as well as climbing and walking robots, equipped with vision systems and sets of tools for cleaning outside surfaces of buildings, windows, filling-in cracks, and spraying-on protective surfaces and painting facades).

6. Building (especially in urban areas) and fitting small dimension tunnels and culverts for utility installations (power network, computer and telephone lines). (What is particularly important here is a problem of location of the working tool, identification and location of obstacles, bypassing obstacles, and often also internal equipment of the built tunnels).

Each structural-task system presented above is, to a differing degree, both in need of and open to automation. The degrees can be increased through unification of elements of the construction which is erected, standardisation and simplification of technological operations, putting them into groups and automating the process of design of the building structure and the construction technology itself, as well as coupling the design with the construction process within a shared information technology system which may allow to use design data to generate algorithms for mechanised and automated machinery and equipment and their systems on the building site.

Work on mechanisation and automation of engineering and construction work has been initiated independently in a number of countries in the seventies as a reaction to success of industrial robotics, which raised high hopes for substantial growth of efficiency in the construction industry, for reduction in the number of accidents, and improvement of working conditions, and making the work itself more attractive. Initially, those activities concentrated principally on developing automatic control systems in various groups of machines and equipment, and on adaptation of industrial robots to selected types of construction work. Those activities have been presented in $[18,19]$.

Basing on the initiative taken in the 70 s and 80 s, it is difficult to talk about essential change in the construction work quality due to introducing automation and mechanisation. It must be stated, though, that a research and science potential has been built, and experience has been gained, which provided a good foundation to a multidimensional approach to the issues of automation and robotisation in construction processes.

At the turn of the $80 \mathrm{~s}$ and the $90 \mathrm{~s}$, the results which had been arrived at were estimated, research problems were indicated, and the necessity of introducing design processes was pointed at, as well as developing construction technologies functionally coherent with the idea of automation and robotisation of construction processes was suggested, basing principally on an ability to perform certain operations many times, repetitively and fast, consisting of simple manipulation activities (for instance, assembly) and transport work, done in the environment of well-known (or well identified) elements of simple spatial characteristics and shape. It was also concluded that the anthropomorphic approach - replacing human activities by activities performed often very similarly by multielement manipulators - did not, in most cases, bring satisfactory effects.

It was proved that, in case of erecting structures in a classical way, certain separate activities could be identified, which could be carried out by individual machines (or manipulators) automatically or remotely controlled. It was started that, also in those cases, one could count on a significant increase in work efficiency, improvement in working conditions and safety of the builders, and on improvement in quality of the work done. Another thing that could be taken into account is reduction of costs, mostly due to the decrease in work load per task, and eliminating or cutting down the need to use scaffolding, security systems, and additional transport equipment.

The development of computer-aided design (CAD) of constructions, and of the methodology of decomposing their structure gave way to new technologies of erecting buildings allowing, on the one hand, to perform certain types of work simultaneously and, on the other, to unify the structure of composition elements and assembly processes using those elements. The traditional approach - beginning with digging trenches, laying foundations, and gradually erecting the carrying elements of the floors (walls, or perhaps pillars and ceilings), supplied by a roof, and then continuing with interior finish - proved to be a serious obstacle to automation of work processes implemented in such a way, which would be efficient and significantly advantageous.

At the turn of the $80 \mathrm{~s}$ and the $90 \mathrm{~s}$ it was concluded that erecting constructions must be tied with simultaneous implementation of the basic tasks, with eliminating or serious reducing the influence of weather conditions on the operation efficiency and quality, essential improvement in the working conditions of the builders, full mechanisation of transport and assembly, and automation of much simpler, but time consuming activities (such as painting, floor floating, etc), as well as those which require precision (for instance, checking the carrying elements, distributing and depositing concrete mix, etc).

Three basic concepts of carrying on construction work based on the roof raised gradually in the course of erecting subsequent floors [19]:

Method 1. "External" - the raised roof is a real crowning of the structure, but inside the roof there is a platform with derricks, manipulators and loading units installed on guides and rails, thanks to which concrete casting work can be done "from above" (floors between levels, carrying pillars), as well as other works, like positioning and assembling walls and partitions, welding structural elements - usually done at the vertical and 
horizontal levels. The whole structure is cyclically raised by means of a system of synchronised hydraulic hoists controlled by a microprocessor system - at the rate of a few to over ten $\mathrm{mm} / \mathrm{min}$.

Method 2. A special roofed, raised platform - a "temporary roof", equipped with transportation devices, loading units and manipulators, with the guides being positions of reference. The platform implements similar tasks as the raised roof.

Method 3. A special raised platform, additionally coupled with a system placed upon it (on top of it) manufacturing smaller prefabricated and structural elements (a "sky factory").

Developing optimal algorithms to control the work of this machinery, in connection with monitoring the space below the platform and the machines by means of devices (scanners) identifying the transported and assembled elements, allows to arrive at a task-function structure which is safe and efficient.

In order to effectively use the above-mentioned methods, apart from performing planning and organisational activities, it is necessary to develop a new approach to fitting all installations inside the erected structure. To tie "fragments" of the installation with the assembled elements constituting the structure at the production stage, and using couplings thanks to which those fragments cam mechanically "self-couple" during the assembly of a level can speed up construction work. A lot of research related to this approach has been recently carried out in Germany, Japan, the USA, and Taiwan.

In Poland, such an approach to the processes of automation and robotisation of construction work, in view of the current economical and social situation, is still groundless, and will not be of much interest to investors and construction companies.

\subsection{Priority research trends}

1. The success of robotics in large-lot production in the machine industry attracted interest in the processes of automation and robotisation of construction work. Nevertheless - due to the differences presented above transferring robotised technologies from one sphere of production to another has not led to noticeable improvement in efficiency and cost reduction.

Only the multiaspect, complex approach to the issues of robotisation in construction industry - beginning at the stage of designing the structure of buildings, their decomposition and unification of the elements, through a simultaneous development of technologies of erecting (assembly) of structures, more "friendly" to robotics, and improvement in builders' working conditions, automating human labour shows the potential for significant improvement of efficiency of construction work - especially in the aspect of shortening the time of investment, amending safety standards, and reducing the risks for external environment.
2. There is no multiaspect approach to the problem of automation and robotisation of construction work in Poland which, in effect, leads to a situation whereby only some selected issues are looked into, which does not provide opportunities in the near future for wider interest in behalf of investors and contractors. It is necessary to create positive climates around those issues beginning with construction design, in order to facilitate the robotisation of construction work itself, through development and organisation of the building site based on an integrated information technology system, and finally, developing complex systems of automated machinery and equipment.

3. Another important task is introduction of automated devices which do particularly hazardous work (for example, where excessive dust or humidity occur) or dangerous work (assembling the carrying elements, work of facades of very tall buildings, etc). In order to justify the advantages of robotisation of such work, it is necessary to include such costs to the economic calculations as sick leaves, medical treatment costs, or even compensation funds for families of workers who suffered fatal accidents, for those who were injured or lost their health on the building site. It is also necessary to establish a legal system which may allow for reducing, for example, the insurance costs when automation and robotisation is used in construction work, this increasing work safety itself.

4. Using global and local information technology and telecommunications network systems (the Internet, intranet, mobile telephone system and traditional telephone network) and safe radio communications for data transfer, passing messages and orders, control signals, and sending information (including video information) can be a new impulse for developing automation and robotisation of construction processes. This provides an opportunity to work on-line of a shared information system available to all participants of the construction system, who are usually dispersed. This system facilitates such tasks as testing, implementation of tasks and control over tasks done by automated machinery and equipment. Work leading towards such an integrated system is currently initiated in the USA, Japan, Spain, under the motto of "E-work in construction information management system".

Uncertain perspectives of economic development in Poland in the near future, excess of still quite cheap labour, and the domination of foreign investors in the basic construction industry production, as well as the Polish affection for traditional construction methods in housing industry, regarded to be ecological, provides little hope for rapid development of automation and robotisation to reach levels close to those observed in recent years in such countries as Japan, USA, Germany. Paradoxically, it provides an opportunity that, in the near future, initiative will be taken to create elements, and a whole system employing automation and robotisation in construction work 


\section{Concluding remarks}

The problems presented in the article are exceptionally complex and, as such, had to be presented in four separate sections: the investment process, the company, the methods and, finally, generally conceived mechanisation. Those issues are interrelated, and can be described by a set of their own specific rules. They are all deeply rooted in market economy which sets out conditions for their development, and the research itself is rooted in the sections mentioned above.

Market economy clearly stimulates not only the recruitment of students, mentioned in the text, and the curricula, but also dictates the subject matter for research.

Postgraduate courses in organisation and management in construction have proved to be a very popular choice recently. Nearly all academic centres in Poland offer postgraduate courses, mostly in real estate estimation.

Courses in Construction Engineering and Management (CE\&M) are now taking a wider perspective (both in their educational and research aspects), upgraded from the issues of researching processes on the building site itself to a higher level, ie researching organisation and management in the investment process, and the operation of the construction company as a whole.

The issues of organisation and management discussed in this paper are covered by CE\&M (or similar specialist fields), while the issues of mechanisation, automation, and robotisation remain in the focus of mechanical or electrical departments. Nevertheless, the course in organisation of automated and robotised work should be offered at construction departments.

Publications and reports show that research in our academic environment follows the changes resulting from the emerging market economy. One can be optimistic about the matters of utilisation of research results and such activities as academic conferences and different types of training.

The material presented above justifies the statement that organisation and management in construction industry, both in their practical and research aspects, have been undergoing a true revival over the last decade.

\section{References}

1. Kapliński, O.; Werner, W.; Kosecki, A.; Biernacki, J.; Kuczmarski, F. Management, organisation and machanisation in construction industry, Proc. of XZVIII conference KILIW PAN and KN PZITB: Opole-Krynica. Politechnika Opolska, 2002 (in printing, in Polish).

2. Kapliński, O. Characteristic of the academic centres engaged in engineering, organisation and economics in construction industry. Problemy Rozwoju Budownictwa, No 1 , 2002, p 41-45 (in Polish)

3. Kaplinski, O.; Zavadskas, E. K. An overview of the problems related to research in construction engineering, man- agement and economics in Poland. Journal of Civil Engineering and Management, Vol VIII, No 4. Vilnius: Technika, 2002.

4. Werner, A. W. Investment process for architects. Oficyna Wydawnicza Politechniki Warszawskiej, Warszawa, 1994 (in Polish).

5. Werner, A. W. Management in investment process. Oficyna Wydawnicza Politechniki Warszawskiej, Warszawa, 1999 (in Polish).

6. Proc. of conference „Risk management”. Strategies of risk management in enterprise - problems at the beginning of XXI century. TNOiK, Bydgoszcz - Ciechocinek, 2001.

7. Proc. of conference ,Technology and organisation in construction industry at the beginning of XXI century", Pulawy, June 21-24, 2001.

8. Zavadskas, E.; Kapliński, O.; Kaklauskas, A.; Brzeziński, J. Expert systems in construction industry. Trends, potential \& application. Vilnius: Technika, 1995.

9. Kapliński, O. Modelling of construction processes. A managerial approach. In: IPPT PAN, Studia z Zakresu Inżynicrii No 43, Warszawa, 1997.

10. Biernacki, J. Actual construction management skills in Poland. Materials of international conference „Professional skills in construction management", Lisbon, May, 1996.

11. Biernacki, J. Decision techniques - state of art. Materials of science conference, Hanzehogeschool-Groningen, Netherlands, November, 1996

12. Barraza, G. A.; Back, W. E.; Mata, F. Probabilistic monitoring of project performance using SS-curves. Journal of Construction Engineering and Management, 3/4, 2000, p 142-148.

13. Wiatr T. Sigmoidal curves in process of project controlling. Proc. of conference "Technological, organizational and economical aspects of construction industry development". Olsztyn-Lańsk. Uniwersytet Warmińsko-Mazurski w Olsztynie, Olsztyn, 2002 (in Polish).

14. Biernacki, J. Perspectives of artificial neoron networks application in analysis of organisational structures. Proc. of conference ,Management and marketing in construction industry", Kraków, 1997 (in Polish).

15. Morecki, A. et al. Ground of robotics - theory and elements of manipulators and robotics, WNT, Warszawa, 1994 (in Polish).

16. Kasprowicz, T.; Kuczmarski, F,; Płocharz, W. The evaluation method of construction machines work quality. International conference on leadership and total quality management in construction and building, Singapore, 6-8 October, 1997.

17. Kuczmarski, F. Formation of machines control for earth works in the aspect parameters improvement on example single-bucket excavator. Dissertation, Wojskowa Akademia Techniczna, Warszawa, 2000

18. Proc. of conferences: V - XV conferences on Problems of working machines development, Zakopane, 1992-2002.

19. Proc. of VIII-XVIIth International Symposiums on Automation and Robotics in Construction, 1991-2001. 